\title{
Human myiasis in an endemic area of Southwestern Ethiopia: Prevalence, knowledge, perceptions and practices
}

\author{
Delenasaw Yewhalaw ${ }^{1}$, Worku Legesse ${ }^{2}$, Solomon Gebre-Selassie ${ }^{3}$, Helmut Kloos ${ }^{4}$
}

\begin{abstract}
Background: Human subcutaneous myiasis is an endemic, understudied disease in Ethiopia.

Objective: The aim of this study was to assess knowledge, perceptions and practices in different urban and rural communities of Jimma Zone, southwestern Ethiopia, related to human myiasis.

Method: A cross-sectional, descriptive, comparative study was carried out during March -June 2005 in 5 urban and 3 rural kebeles in Jimma Zone. Kebeles were chosen by random sampling and a total of 1,272 households were selected by systematic random sampling technique for interview.

Results: Most subjects (60.0\%) mentioned lying on damp soil as the cause of myiasis. More urban than rural communities who wore un-ironed clothes had myiais infestation $(\mathrm{p}<0.05)$. Myiasis was reported to be common in the lower extremities (65.6\%), upper extremities (56.7\%), abdomen (48.9\%) and back (34.9\%). A total of 86\% dwellers responded that myiasis was more common during the wet season. More than half of the interviewees were knowledgeable about the clinical presentation of the disease. The most common signs and symptoms were itching (94.0\%), pus discharge (82.9\%) and papules $(79.5 \%)$. The majority $(87.9 \%)$ of the study subjects treated infestations with hot matches. Wearing dry clothes (38.6\%) was reported to be effective preventive measure. Nearly $64.8 \%$ of the rural and $68.7 \%$ of the urban communities knew that human subcutaneous myiasis is preventable.
\end{abstract}

Conclusion: Due to the low levels of knowledge about myiasis, we recommend that community health education programs be developed through the health services to raise the awareness levels about this infestation to the general population. [Ethiop.J.Health Dev. 2007;21(2):166-172]

\section{Introduction}

Myiasis, known as hultukko by the Oromos of Southwestern Ethiopia and as yebissana til by the Amharas, is an infestation of organs and tissues of humans and animals by diptera larvae hatching from eggs laid by non - biting flies on wet clothes, animal feces and other humid objects. The larvae hatch and penetrate the skin, causing inflamed nodules in the host. When mature, they wriggle out and fall to the ground to pupate (1). Infestations may be classified as accidental, facultative or obligate. Human cases are considered obligate and often result in subcutaneous infestation or furuncular myiasis (2-5). Two species of flies may serve as carriers: Cardilobia anthropophaga Grunberg (Diptera: Calliphoridae) in Africa and Dermatobia hominis (Diptera: Cuterbidae) in South America (6). C. anthropophaga, the tumbu fly, is an obligate parasite that occurs through most of sub-Saharan Africa (4).

Infestation by $C$. anthropophaga larvae causes persistent pruritic and painful furuncular lesions with central necrosis and purulent discharge. Skin infestation may involve several larvae and any part of the body may be affected (7). Initially the lesion starts as a small papule containing the larvae which may be itchy or pricking at intervals. After 24 hours of larval deposition, a small slightly reddened papule $2-3 \mathrm{~mm}$ in diameter appears which enlarges into a dome shaped nodule that conveys a stinging sensation and considerable pain. The nodules are shiny and black (8). As the papule increases in size, the recurring symptoms may cause sleeplessness. Local lymphadenopathy, fever and general malaise may occur. In the orbit, the larvae can cause serious pathology, including ophthalomyasis (9), including loss of the eye and fatal cerebral myiasis in children (7). Extraction of larvae and application of vaseline or a drop of oil are effective therapeutic measures for primary infestations and antibiotics for secondary infections (10).

In Ethiopia, little is known about human myiasis infestation and its distribution. Mehari (11) reported a $21 \%$ prevalence rate of subcutaneous myiasis from an interview survey conducted among 174 students at Jimma Institute of Health Sciences in Jimma town. However, there is no published and documented information on knowledge, perceptions, and practice of human myiasis in both urban and rural communities. Therefore, the present study was conducted to assess community perceptions and practices about human myiasis, as well as its prevalence and designed with a view to develop community health education programs.

\section{Methods}

The study was carried out during March-June 2005 in

\footnotetext{
${ }^{1}$ Department of Biology, Faculty of Natural Sciences, Jimma University, P.O. Box 378, Jimma, Ethiopia, e-mail: delenasawye $@$ yahoo.com; ${ }^{2}$ School of Environmental Health, Faculty Public Health, Jimma University, P. O. Box 378, Jimma, Ethiopia, e-mail: 1worku@yahoo.com; ${ }^{3}$ Department of Microbiology, Immunology and Parasitology, Faculty of Medicine, Addis Ababa University, P. O. Box 21656/1000, Addis Ababa, Ethiopia, e-mail: solomongst@yahoo.com; ${ }^{4}$ Department of Epidemiology and Biostatistics, University of California, San Francisco, CA 94143, USA
} 
Jimma town and 3 nearby rural kebeles in Jimma Zone, which are located in the humid highlands of southwestern Ethiopia. Administratively, the zone is subdivided into 13 woredas (districts). According to the Central Statistical Authority of Ethiopia (12), the population of the zone was estimated to be 2,779,108 in 2006. The livelihood of the people of the zone is based on subsistence mixed agriculture involving crop cultivation and animal husbandry. The staples are maize, Enset (Ensete ventricosum) and other root crops, with supplemental cattle and small livestock raising. Coffee, grown on plantations and in forests, is the major cash crop. Jimma, the administrative center of Jimma Zone, is divided into 13 kebeles and had an estimated population of 110,000 in 2002/03 (12).

A household-based, cross-sectional descriptive study design was employed to assess community perceptions and practices regarding causation (sources of infestations), clinical signs and symptoms, modes of transmissions, treatment measures and prevention of human myiasis infestations.

The study population included communities living in 5 of the 13 kebeles of Jimma town and of 3 rural kebeles located 4-5 km east and west of the town. Using simple random sampling technique, 5 urban kebeles and 3 rural kebeles (peasant associations) were selected on the basis of accessibility for urban/rural comparison. The sample size was determined using the formula for estimating a single proportion of 3357 households of urban communities taking into account $\alpha=0.05$ and $80 \%$ power detection (13). Thus the sample size for the urban community was determined to be 636 households. An equal number of households were selected from 3 rural kebeles giving a total sample size of 1272 after adding $5 \%$ for an anticipated non-response rate. The allotted sample size for the 3 urban kebeles was obtained using a probability proportional to the population size of the selected kebeles. Systematic sampling technique was employed to select households after random selection of the first sample household. The sampling interval was 5 households for urban kebeles and 3 households for the rural kebeles.

Interviews were conducted with one available adult member in each household using a semi-structured, pretested interview schedule. Closed-ended questions were prepared in Oromiffa and Amharic to be used during interviews. Face-to-face interviews were carried out by trained interviewers ( 3 male and 2 female students from Jimma University) who were conversant to the local Oromiffa and Amharic languages and accompanied by the investigators. In both urban and rural kebeles, all selected study subjects agreed to participate in the study.

The collected data were edited by the investigators and entered into a computer. Data were analyzed using Excel2003 Microsoft Corp. and SPSS for Windows, version 11.0 programs.

\section{Results}

A total of 1,272 persons in the selected 1,272 households (636 urban and 636 rural) were interviewed, giving a $100 \%$ response rate. Interviewers revisited each selected household in the same day or the following day if selected houses were locked or no one found at home. Most of the respondents were in the age group of 15-44 $(75.9 \%)$, female $(56.1 \%)$, married $(68 \%)$, literate (63.5\%), Oromo (60.2\%) and Moslems (54.1\%), but considerably more single persons, males, literate persons, and members of the Orthodox religion and Amhara ethnic group lived in the town (Table 1).

Self-reported life-prevalence of human myiasis was similarly high both in the rural $(55.8 \%)$ and urban $(50.8 \%)$ areas. But infection rates were higher among females in rural areas whereas they were higher in males in the urban kebeles and showed a variable age distribution in the two areas. Whereas rates were above $20 \%$ in both pre-school and school children and gradually declined among both males and females after age 14 years in the rural communities, they peaked at 15 44 age groups in the urban kebeles (Table 2). The highest prevalence rate was found during the beginning of the rainy season.

Relatively more urban than rural respondents provided correct answers to the question on the perceived causes (or transmission routes) of myiasis, with $69.8 \%$ vs $50.9 \%$ mentioning lying on damp soil, $27.2 \%$ vs $10.7 \%$ contact with contaminated damp cloth, and 9.8 vs $0 \%$ un-ironed clothes in the urban and rural communities, respectively. Similarly, fewer urban than rural respondents provided wrong answers, with the exception of the response "dirty persons" (Table 3). Closest to one-fifth of the respondents did not know any of the transmission routes of human myiasis.

Nearly two-thirds $(65.6 \%)$ of the study population correctly named the lower extremities. In addition, $56.7 \%$ of them mentioned the upper extremities, $48.9 \%$ the abdomen, $13.7 \%$ the head and neck, $11.2 \%$ the chest, and $34.9 \%$ the back as the most common sites of fly bites, with relatively small variations between the urban and rural communities. Fewer than $20 \%$ of each considered the head, neck and chest regions to be involved.

When asked about the treatment of human myiasis, $88.0 \%$ of the respondents mentioned holding heated match sticks over the area of the lesion, $46.9 \%$ digital or pressure extraction and $13.4 \%$ application of niger seed respectively for (Guizotia abyssinica (L.f) Cass., Asteraceae), Ethiopian kale (Brassica carinata, A. Br., 
Table 1: Socio-demographic characteristics of 1272 adult respondents, by urban and rural residence, Jimma, 2005

\begin{tabular}{|c|c|c|c|}
\hline Characteristics & $\begin{array}{l}\text { Urban }(n=636) \\
\text { No }(\%)\end{array}$ & $\begin{array}{l}\text { Rural }(n=636) \\
\text { No }(\%)\end{array}$ & $\begin{array}{l}\text { Total }(\mathrm{N}=1272) \\
\text { No }(\%)\end{array}$ \\
\hline \multicolumn{4}{|l|}{ Marital status } \\
\hline Single & $247(38.8)$ & $69(10.8)$ & $316(24.9)$ \\
\hline Married & $359(56.4)$ & $506(79.6)$ & $865(68.0)$ \\
\hline Divorced & $27(4.2)$ & $37(5.8)$ & $64(5.0)$ \\
\hline Widowed & $3(0.5)$ & $24(3.8)$ & $27(2.1)$ \\
\hline \multicolumn{4}{|l|}{ Sex } \\
\hline Male & $230(36.2)$ & $329(51.7)$ & $559(43.9)$ \\
\hline Female & $406(63.8)$ & $307(48.3)$ & $713(56.1)$ \\
\hline \multicolumn{4}{|l|}{ Age (years) } \\
\hline $15-44$ & $500(78.6)$ & $466(73.3)$ & $966(75.9)$ \\
\hline $45-60$ & $80(12.6)$ & $102(16.0)$ & $182(14.3)$ \\
\hline$>60$ & $56(8.8)$ & $68(10.7)$ & $124(9.8)$ \\
\hline \multicolumn{4}{|c|}{ Educational status } \\
\hline Illiterate & $57(9.0)$ & $407(64.0)$ & $464(36.5)$ \\
\hline Literate & $579(91.0)$ & $229(28.3)$ & $808(63.5)$ \\
\hline \multicolumn{4}{|l|}{ Religion } \\
\hline Orthodox & $412(64.8)$ & $65(10.2)$ & $477(37.5)$ \\
\hline Moslem & $120(18.9)$ & $568(89.3)$ & $688(54.1)$ \\
\hline Catholic & $7(1.1)$ & $0(0.0)$ & $7(0.5)$ \\
\hline Protestant & $97(15.2)$ & $3(0.5)$ & $100(7.9)$ \\
\hline \multicolumn{4}{|l|}{ Ethnicity } \\
\hline Oromo & $192(30.2)$ & $574(90.3)$ & $766(60.2)$ \\
\hline Amhara & $214(33.6)$ & $26(4.1)$ & 240 (18.9) \\
\hline Dawro & $30(4.7)$ & $18(2.8)$ & $48(3.8)$ \\
\hline Kaffa & $50(7.9)$ & $3(0.5)$ & $53(4.1)$ \\
\hline Yem & $52(8.2)$ & $9(1.4)$ & 61 (4.8) \\
\hline Gurage & 72 (11.3) & $0(0.0)$ & $72(5.7)$ \\
\hline Tigre & $23(3.6)$ & $6(0.9)$ & $29(2.3)$ \\
\hline Others & $3(0.5)$ & $0(0.0)$ & $3(0.2)$ \\
\hline Total & $636(100.0)$ & $636(100.0)$ & $1272(100.0)$ \\
\hline
\end{tabular}

Table 2: Age- sex specific prevalence of human myiasis self-reported by 1272 respondents, by rural and urban residence, Jimma, 2005

\begin{tabular}{|c|c|c|c|c|c|c|}
\hline & \multicolumn{2}{|c|}{ Rural } & \multicolumn{2}{|c|}{ Urban } & \multicolumn{2}{|c|}{ Total } \\
\hline & $\begin{array}{l}\text { Male } \\
(n=329) \\
\text { No (\%) }\end{array}$ & $\begin{array}{l}\text { Female } \\
(n=307) \\
\text { No (\%) }\end{array}$ & $\begin{array}{l}\text { Male } \\
(n=230) \\
\text { No (\%) }\end{array}$ & $\begin{array}{l}\text { Female } \\
(n=406) \\
\text { No (\%) }\end{array}$ & $\begin{array}{l}\text { Rural } \\
(n=636) \\
\text { No (\%) }\end{array}$ & $\begin{array}{l}\text { Urban } \\
(n=636) \\
\text { No (\%) }\end{array}$ \\
\hline$<5$ & $84(25.5)$ & $66(21.5)$ & $31(13.5)$ & $21(5.2)$ & $150(23.6)$ & $52(8.3)$ \\
\hline $5-14$ & $63(19.2)$ & $67(21.8)$ & $32(13.9)$ & $28(6.9)$ & $130(20.4)$ & $60(9.4)$ \\
\hline $15-44$ & $25(7.6)$ & $40(13.0)$ & $57(24.8)$ & $119(29.3)$ & $65(10.2)$ & $176(27.7)$ \\
\hline $45-59$ & $2(0.6)$ & $6(2.0)$ & $2(0.9)$ & 21(5.2 & $8(1.3)$ & $23(3.6)$ \\
\hline$>60$ & 0 & $2(0.7)$ & $5(2.2)$ & $7(1.7)$ & $2(0.3)$ & $12(1.9)$ \\
\hline Total & 174(52.9) & 181(59.0) & 127(55.2) & 196(48.3) & $355(55.8)$ & $323(50.8)$ \\
\hline
\end{tabular}

Brassicaceae) and Linum usitatissimum L. oils (Table 4). Few $(1.3 \%$ of rural and $7.7 \%$ of urban) respondents practiced needle extraction of the larvae.

Slightly over $60.8 \%$ of the rural and $68.7 \%$ of the urban respondents knew methods of prevention of human myiasis but $20.4 \%$ of the study population did not know any methods. Significantly $(\mathrm{P}<0.05)$ more rural $(30.1 \%)$ than urban $(10.7 \%)$ respondents said that they do not know myiasis be completely prevented. About two-third of the respondents mentioned avoidance of drying clothes on the ground (66.7\% rural, $64.5 \%$ urban) and nearly a third of wearing dried clothes (18.9\% rural, 58.3\% urban) are preventive measures for transmission of myiasis (Table 5). Significantly more urban respondents reported avoidance of sunbathing and larger numbers of rural dwellers considered use of insecticides an effective preventive measure. Only members of urban communities mentioned ironing of clothes (13.8\%) as a preventive measure. 
Table 3: Knowledge of signs and symptoms, causes and location of myiasis skin lesions of 1272 rural and urban respondents, Jimma, 2005

\begin{tabular}{lrrr}
\hline Signs and Symptoms & $\begin{array}{r}\text { Rural } \\
(\mathbf{n}=636) \\
\text { No (\%) }\end{array}$ & $\begin{array}{r}\text { Urban } \\
(\mathbf{n}=636) \\
\text { No (\%) }\end{array}$ & $\begin{array}{r}\text { Total } \\
(\mathbf{N}=\mathbf{1 2 7 2}) \\
\text { No (\%) }\end{array}$ \\
\hline Symptoms & & & \\
Fever & $49(7.7)$ & $11(1.7)$ & $50(4.7)^{\star}$ \\
Papule & $416(65.4)$ & $595(93.6)$ & $1011(79.5)$ \\
Itching & $583(91.7)$ & $613(96.4)$ & $1196(94.0)$ \\
Pus discharge & $565(88.8)$ & $489(76.9)$ & $1054(82.9)$ \\
Bleeding & $17(2.7)$ & $14(2.2)$ & $31(2.4)$ \\
Lymphadenopathy & $2(0.3)$ & $3(0.5)$ & $5(0.4)$ \\
Others & $0(0.0)$ & $5(0.8)$ & $5(0.4)$ \\
Causes & & & \\
Fly bite & $191(30.0)$ & $7(1.1)$ & $198(15.6)^{\star}$ \\
Dirty persons & $155(24.4)$ & $334(52.5)$ & $489(38.4)$ \\
Contaminated damp cloth & $68(10.7)$ & $173(27.2)$ & $241(19.0)$ \\
Unironed clothes & $0(0.0)$ & $62(9.8)$ & $62(4.9)$ \\
Contaminated food and water & $1(0.2)$ & $14(2.2)$ & $15(1.2)$ \\
Lying on damp soil & $324(50.9)$ & $444(69.8)$ & $768(60.4)$ \\
Animals & $22(3.5)$ & $0(0.0)$ & $22(1.7)$ \\
Dirty, stagnant water & $1(0.2)$ & $17(2.7)$ & $18(1.4)$ \\
Don't know & $139(21.9)$ & $107(16.8)$ & $246(19.3)$ \\
Others & $16(2.5)$ & $4(0.6)$ & $20(1.6)$ \\
Location of skin lesions & & & \\
Head and neck & & $79(12.4)$ & $174\left((13.7)^{\star}\right.$ \\
Chest & $95(14.9)$ & $84(13.2)$ & $142(11.2)$ \\
Back & $58(9.1)$ & $253(39.8)$ & $444(34.9)$ \\
Abdomen & $191(30.0)$ & $364(57.2)$ & $622(48.9)$ \\
Upper extremities & $258(40.6)$ & $310(48.7)$ & $721(56.7)$ \\
Lower extremities & $411(64.6)$ & $458(72.0)$ & $834(65.6)$ \\
\hline *Sum exceeds 100\% due to multiple responses & $376(59.1)$ & &
\end{tabular}

Table 4: Knowledge and practice of treatment of myiasis of 1272 rural and urban respondents, Jimma, 2005

\begin{tabular}{llll}
\hline Treatment & $\begin{array}{l}\text { Rural }(\mathbf{n}=636) \\
\text { No }(\%)\end{array}$ & $\begin{array}{l}\text { Urban }(\mathbf{n}=636) \\
\text { No }(\%)\end{array}$ & $\begin{array}{l}\text { Total }(\mathbf{n}=1272) \\
\text { No }(\%)\end{array}$ \\
\hline Application of Vaseline & $0(0.0)$ & $17(2.7)$ & $17(1.3)^{\star}$ \\
Application of oil & $159(25.0)$ & $12(1.9)$ & $171(13.4)$ \\
Using strips & $2(0.3)$ & $0(0.0)$ & $2(0.2)$ \\
Heating with match sticks & $535(84.1)$ & $583(91.7)$ & $1118(87.9)$ \\
Needle extraction & $8(1.3)$ & $49(7.7)$ & $57(4.5)$ \\
Incision by physician & $1(0.2)$ & $3(0.5)$ & $4(0.3)$ \\
Manual extraction & $553(87.0)$ & $44(6.9)$ & $597(46.9)$ \\
Others & $19(3.0)$ & $2(0.3)$ & $21(1.7)$ \\
\hline
\end{tabular}

* Sum exceeds $100 \%$ due to multiple responses

The majority of both the urban (94.7\%) and rural (77.3\%) respondents recognized that human myiasis occurs during the two rainy seasons, which usually occur in Jimma Zone from June to September and from February to May. Quite high proportion (88\%) of the respondents was willing to participate in and support a community health education program, if such program would be launched in their communities (Table 5).

The most common signs and symptoms of myiasis were said to be itching $(94.0 \%)$, pus discharge $(82.9 \%)$ and papules $(79.5 \%)$. The distribution of these and lesser symptoms showed no major differences between rural and urban areas (Table 3). 


\begin{tabular}{|c|c|c|c|}
\hline Variables & $\begin{array}{r}\text { Rural } \\
(n=636) \\
\text { No }(\%)\end{array}$ & $\begin{array}{r}\text { Urban } \\
(n=636) \\
\text { No }(\%)\end{array}$ & $\begin{array}{r}\text { Total } \\
(n=1272) \\
\text { No }(\%)\end{array}$ \\
\hline \multicolumn{4}{|l|}{ Preventability } \\
\hline Yes & $387(60.8)$ & $437(68.7)$ & $824(64.8)$ \\
\hline No & $57(9.0)$ & $131(20.6)$ & $188(14.8)$ \\
\hline \multicolumn{3}{|l|}{ Preventive behavior } & $260(20.4)$ \\
\hline Insecticide use & $64(10.1)$ & $11(1.7)$ & $75(5.9)^{*}$ \\
\hline Avoid sunbathing & 74(11.6) & $27(4.3)$ & 101(7.9) \\
\hline Wearing dried clothes & $120(18.9)$ & $371(58.3)$ & $491(38.6)$ \\
\hline $\begin{array}{l}\text { Ironing clothing } \\
\text { Do not dry clothes on the } \\
\text { ground }\end{array}$ & $424(66.7)$ & $410(64.5)$ & $834(65.6)$ \\
\hline \multicolumn{4}{|l|}{ Transmission season } \\
\hline Wet season & $492(77.3)$ & $602(94.7)$ & 1094(86.0) \\
\hline Dry season & $144(22.7)$ & $34(5.4)$ & $178(14.0)$ \\
\hline All the time & $0(0.0)$ & $0(0.0)$ & $0(0.0)$ \\
\hline Don't know & $0(0.0)$ & $0(0.0)$ & $0(0.0)$ \\
\hline \multicolumn{4}{|l|}{ Willingness to participate } \\
\hline Yes & $618(97.3)$ & $500(78.6)$ & 1118(87.9) \\
\hline No & $9(1.4)$ & 119(18.8) & 128(10.1) \\
\hline No response & $9(1.4)$ & $17(2.6)$ & $26(2.0)$ \\
\hline
\end{tabular}

* Sum exceeds $100 \%$ due to multiple responses

\section{Discussion}

The results of this study reveal high levels of knowledge about the cause, signs and symptoms, and treatment of human myiasis but also misconceptions that need to be addressed in any prevention and control program. Having lived in the myiasis-endemic area of Jimma Zone, many people appear to have learned over the years to associate larval skin infestations with lying on damp soil, wearing damp clothing contaminated with excrements and unironed clothing.

The responses provided by the participants of this study on signs and symptoms tend to corroborate with the findings by Mehari (11), who reported that papules, pain, itching and pus discharge were the main clinical presentations of human subcutaneous myiasis in another part of Ethiopia. Other studies showed that wearing damp clothes or resting in sandy areas that are likely to have been soiled increase exposure risk in endemic areas, since the flies oviposit usually on sand soiled by urine and feces (6). Alexander (14) reported that wearing unironed clothes was a cause of myiasis as tumbu flies usually oviposit eggs on unwashed clothes contaminated with urine or feces and clothing laid on the ground or hanging on the washing line to dry.
Some respondents from urban communities of the present study subjects recognized un-ironed clothes as a possible source of myiasis infestation. Radcliffe (15) recommended that all personal laundry be ironed on both sides after drying to kill the larvae that cause subcutaneous myiasis. The relatively higher proportion $(19.3 \%)$ of all respondents who did not know any exposure risks points out the need to develop health education programs to increase awareness of myiasis and promote preventive behavior in endemic communities.

The due emphasis given by the respondents put on the vulnerability of the extremities; abdomen and back to skin lesions may be due to the greater exposure of these body parts, which may be more easily reached by the larvae, especially when contaminated clothes are worn. Other studies reported that although infestation may occur on any part of the body in contact with the larvae, the feet, buttocks and back are the more commonly affected sites $(10,12)$.

The high prevalence of myiasis in rural children below 15 years of age and low rates in older people in both area is agreed with the work of Blacklock and Thompson (16), who documented that a form of acquired immunity 
developed in persons whose skin had been invaded by $C$. anthropophaga. They reported that the infestation was common in children and newcomers to endemic areas of any age, older natives who had been infested when young were less affected. The high self-reported prevalence of myiasis in both rural and urban areas in Jimma Zone is due to the timing of this study undertaken during the rainy season, which favors larval development and survival. The high prevalence also suggests high awareness and knowledge levels were gained in the study communities outside the formal health services. The higher prevalence reported by pre-school and school children in rural than urban communities may be due to earlier exposure of rural residents to infective larvae as part of their agricultural and domestic activities and concomitant early acquired immunity. Urban dwellers, on the other hand, may be more protected in the urban socio-economic and physical environment during childhood and become into closer contact with infective larvae after leaving elementary school and starting to work.

The considerable preventive knowledge of the study members reflects an understanding of female fly feeding preference for urine- and feces-contaminated soil (16) and oviposition in dark places (17). More than $60 \%$ of the study subjects in both urban and rural communities knew one or more preventive measures for subcutaneous myiasis. The fact that one-fifth of the respondents did not know any preventive measures appears to be due in part to little or no formal education or limited healthpromoting information from health services in the absence of a health education program dealing with human myiasis in Ethiopia. Most respondents were knowledgeable about the treatment of myiasis. Both communities mentioned heating the lesion with match sticks as the most common treatment of the disease. The heat entices the tumbu fly (putsi fly) larvae to leave the cutaneous tissue far enough to be removed with small forceps (6). In this study, application of different kinds of oils was also mentioned as an effective method of treatment. Other studies reported that indigenous people in endemic areas bind a piece of pork fat over the lesion to induce the larvae to emerge (18) or suffocate the larvae by applying liquid paraffin, petroleum jelly or mineral oil or apply grease over the spiracles, which stops their oxygen supply and induces the larvae to partly extrude from the lesion $(19,20)$.

The proportion of rural respondents (86.9\%) who practiced digital/pressure extraction was by far greater than that in urban communities $(7.0 \%)$. This practice may worsen the situation as attempts to expel the larvae by pressure on or around the lesions can result in secondary infections, abscesses and even fatal outcomes (21), and maceration of the larvae may also cause severe inflammatory reactions $(21,22$,$) .$
In this study, the treatment practiced by the community to remove the fly larvae intact using needles is a cause of concern. Although the proportion of respondents $(7.7 \%$ rural, $1.2 \%$ urban) who practiced digital extraction was relatively low, this practice may result in the transmission of HIV and other infectious micro-organisms, especially if these needles are used by different persons (23).

The general agreement made by among respondents about the seasonality of this skin infestation may be attributed to increase contact between non-human hosts of the fly larvae and possibly greater survival of both flies and larvae during the wet season. Blacklock and Thompson (16) reported that the seasonal distribution of human myiasis was associated with rat burrows being flooded and rats being in closer contact with human habitations.

It is not clear from the results if the higher levels of knowledge among urban residents are due to their presumably better health services coverage or higher socio-economic level than that of rural populations.

In conclusion, this study indicates a higher prevalence of myiasis in Jimma Zone and highlights the need for further studies aimed at assessing the extent of the myiasis problem in other parts of Ethiopia. This should include identifying relevant local knowledge, perceptions and health behaviors towards further raising community awareness about this preventable health problem and promoting, and developing cost-effective and feasible interventions. The information obtained through such studies may form the basis for innovative community based health education programs by the health services and schools. The high infestation rates among susceptible school-aged children warrant particular attention.

\section{Acknowledgements}

We are grateful to the Research and Publications Office of Jimma University for funding the research project. We also thank Ato Estifanos Kebede, School of Laboratory Technology, Jimma University for his comments.

\section{References}

1. Zumpt F. Myiasis in man and animals in the Old World. Butterworth, London, 1965.

2. Goddard J. Physicians guide to arthropods of medical importance. CRC Press, Boca Raton, Florida.

3. James MT. The flies that cause myiasis in man. US Department of Agriculture. Miscellaneous Publication 631, Washington, DC, 1947.

4. Baird JK, Baird CR, Sabrosky CW. North American cuterebrid myiasis: Report of seventeen new infections of human beings and review of the disease. J Am Acad Dermatol 1989;21:763-772.

5. Cornet M, Florent M, Lefebvre A, Wertheimer C, Perez-Eid C, Bangs MJ, Bouvet A. Ethiop.J.Health Dev. 2007;21(2) 
Tracheopulmonary myiasis caused by a mature thirdinstar Cuterebra larva: Case report and review. J Clin Microbiol 2003;41:5810-5812.

6. Brewer TF, Wilson ME, Gonzalez E, Felsentien D. Bacon therapy and furuncular myiasis. J Am Med Assoc 1993;270:2087-2088.

7. Wily GS, Glover SC. Myiasis due to tumbu fly larvae. Lancet 1982;2:1130-1131.

8. Nunn P. Tangling with tumbu fly larvae. Lancet 1994;343:676.

9. Currier RW, Johnson WA, Rowley WA, Laudenbach CW. Internal ophthalmomyiasis and treatment by laser photocoagulation: A case report. Am J Trop Med Hyg 1995;52:311-313.

10. Harman RRM, Vollum D. The skin. In: EHO Parry (ed.); Principles of Medicine in Africa, 2nd edition. Oxford University Press, Oxford, 1986:622-644.

11. Mehari S. Cutaneous myiasis among medical students of health sciences, Ethiopia. Bull Jimma Institute of Health Sciences. 1992;2:105-110.

12. Central Statistical Authority (CSA). The 1994 Population and Housing Census of Ethiopia. Results at Regional Level. Vol. 1. Central Statistical Authority, Addis Ababa, Ethiopia, 1998.

13. Jekel JF, Katt DL, Elmore JG. Epidemiology, Biostatistics and Preventive Medicine. Philadelphia, WB Sanders, 2003:184-189.
14. Alexander JD. Arthropods and human skin. William Cowes Limited, London, 1984.

15. Radcliffe W. Tumbu fly. Br Med J 1972;11:164.

16. Blacklock AH, Thompson MJ. A study of the tumbu fly, Cardylobia anthropophaga Grunberg in Sierra Leone. Ann Trop Med Parasitol 1923;17:443-502.

17. Zumpt F. The tumbu fly, Cardylobia anthropophaga (Blanchard) in Southern Africa. S Afr Med J 1959;33:862-865.

18. Konotey-Ahulu FID, Frimpong M, Dodu SRA. Myiasis from Cardylobia anthropophaga. Ghana Med. J 1967;6:10-12.

19. Ruch DM. Botfly myiasis. Arch Dermatol 1967;96:677-680.

20. White GB. Flies causing myiasis. In: GC Cook, AI Zumla (eds). Manson's Tropical Diseases, 21st ed. W B Saunders, London, 2003:1728-1729.

21. Gill GV. Myiasis. In: GV Gill, NJ Beeching (eds). Lecture Notes on Tropical Medicine. $5^{\text {th }}$ ed. Blackwell, Oxford, 2004:282-283.

22. Adams JL. Tropical cutaneous myiasis in man. JAMA 1904;42:947- 949.

23. Gisselquist D, Rothenberg R, Potterat J, Drucker E. Non-sexual transmission has been overlooked in developing countries. Br Med J 2002;324:235. 
